CLINICAL APPLICATION OF KBAI IN DIABETIC CHILDREN, ITS IMPORTANCE IN THE REMISSION PERIOD. Ramos Olga, Sires J .M., Knopf C., Cresto J.C., de Naajo S. Unidad de Endocrinología. Htal. Gral. de Kiños"Dr. Pedro de Elizalde". Buenos Aires. Argentina.

The objective of our experiences has been to relate $\mathrm{HbAl}$ value with the degree of control in diabetic patients. This control was based on clinical examinations, daily glycosuria and ketonuria, glycemias and blood lipids levels. Eighty-eight patients were studied, 8 males and 50 females (age: 1 to 19 years). All of them except 3 were receiving NPH Insulin. The 3 patients who did not receive insulin were in a remission period and maintained only on a diet. Since no differences were found in the HbAl values in both sexes, these were considered jointly. The values found were $14.4 \pm 2.74$ in diabetics and $7.4 \pm 1.5$ in normals. Close relationship was found between the degree of control and the values of libAl. Patients with poor control presented high thal values and patients with good control showed low HbAl. It is interesting to remark that HbAl values were low during the remission period and increased at the end of it. The determination of IfbAl is a good control tool for the diabetic patient and also serves as guidance for its treatment and education.

AGE OF MENARCHE IN URBAN ARGENTINIAN GIRLS. Lejarraga H. (1), Cusminsky M. ("), Sanchirico F. ("): (') Fundacion. Cesni Centro de Estudios de Nutrición Infantil. Buenos Aires. Argentina. (") Hospital Especializado Noel Sbarra. La Plata. Argentina.

Age of menarche is an adequate indicator of physical maturity in population groups. Until now, there has been no information on age of menarche taken from a representative local sample of Argentinian girls. Hence a cross-sectional survey was carried out on 6494 girls aged 8.0 to 19.0 years, attending all private and public secondary schoold and all public primary schoold in La Plata city, Argentina. This sample predominantly includes girls from medium socio-economic levels. Probit analysis was carried out for calculations: mean age of menarche \pm standard error and standard deviation was $12.5 \pm 0.05$ and 1.22 years respectively. These values suggest a relatively early age of menarche in local girls as compared to those reported previously from many other populations in the world.

\section{SEXUAL MATURATION IN 10 TO 19 YEARS OLD CHILDREN.}

Sexual maturation was studied in 6794 children 10 to 19 years old ( 3416 boys and 3378 girls). They were school children of mixed socio-economic background in the County of Santo Andre, State of Sao Paulo (Brazil) during 1978. In males the parameters studied were: genital development, appearance of pubic, auxillary and facial hair and testicular volume. In females the parameters studied were: breast developnent, appearance of pubic and axillary hair and menarche. Genitals, breast and pubic hair were graded as by Tanner and testicular volume was measured with an orchidometer.

In both sexes great variability of sexual development was observed related to age. Median ages (years) calculated with probit analysis are:

males - 9.1 for genital development, 11.4 for pubic hair 13.3 for axillary hair and 14.5 for facial hair.

females -9.7 breast development, 9.8 for pubic hair, 10.5 for axillary hair and 12.4 for menarche.
PUBERTY IN MALE PATIENTS WITH HYPOPITUITARISNi. Martínez, Alicia, Heinrich J.J., Pellizzari, Eliana, Rivarola, Mi.A. and Bergada, C. División Endocrinología. CEDIE. Hoapital de Niños. Buenos Aires. Argentina.

The characteristics of pubertal development of 50 male patients: 17 with isolated growth hormone deficiency (IGHD) and 39 with multiple hormone deficiencies (MHD) were studied. 17 patients ( 7 IGHD and $10 \mathrm{MHD}$ ) started their puberty at a mean chronological age of $14.92 \pm 1.24 \mathrm{yr}(\overline{\mathrm{x}}$ bone age $10.41 \pm 1.50 \mathrm{yr})$ and achieved pubertal stage 5 at $19.22 \pm 1.58 \mathrm{yr}$ ( $\bar{x}$ bone age $15.86 \pm 1.48 \mathrm{yr})$. Adult stage was reached in an average time of $4.09 \pm 1.07 \mathrm{yr}$ (range 2.41 to $5.57 \mathrm{yr}$ ). Plasma testosterone 1evels at different stages of puberty were: G1:41.23 +7.35 , G2: $99.86 \pm 12.80, \mathrm{C} 3: 450.59 \pm 95.58, \mathrm{G} 4: 618.87 \pm 97.46, \mathrm{G} 5: 833.4 \mathrm{O}_{ \pm}$ $71.39 \mathrm{ng} / \mathrm{dl}$. These values did not differ from the mean of normal children in the same pubertal stage. 15 patients without pubertal changes were treated with HCG. Plasma testosterone levels at 1,3 and 12 months of therapy were $466+118.38,1046+239.11$ and $894 \pm 150.23 \mathrm{ng} / \mathrm{d} 1$ respectively. When treatment was interrupted, with a bone age over $14 \mathrm{yr}$ in all of them, testosterone decreased to/pubertal levels. Conclusions: Puberty in those patients who completed it spontaneously was similar to normal except for the chronological age of onset. i:CG therapy is useful ciency and to confirm this diagnosis.

EVALUATION OF DISTAL TUBULAR ${ }^{+}$EXCRETION BY MEANS OF THE ALCALINE OVERLOAD TEST. Voyer L.E., Luiten Irene, Fellertas Ines. FLIP. Hospital de Pediatria "P. de Elizalde". Buenos Aires. Argentina.

Forty eight healthychildren and twelve with several pathological states were studied. To all of them, an alcaline overload was made by means of $\mathrm{NaCO}_{3} \mathrm{H} 3 \mathrm{mEq} / \mathrm{Kg}$ and the difference between urine and serum $\mathrm{pCO}_{2}$ was measured by a radiometer $\mathrm{pCO}_{2}$ electrode after the alcalinization of urine was obtained. Fur thermore, children with pathological states were submitted in a different day to a short test for urinary acidification with an monium chloride. Children with low capacity for urine acidification showed low $\mathrm{pCO}_{2}$ (U-S) values: $10.1+4.9 \mathrm{~mm} \mathrm{Hg}$. as compared with the normals: $61.97 \pm 3.57 \mathrm{~mm}$ Hg. No significant differences were seen between normal infants and children.

The test is considered a simple and useful method to detect abnormalities in the distal $\mathrm{u}^{+}$excretion capacity and can be performed while testing/measure the reabsorption level of $\mathrm{CO}_{3} \mathrm{H}^{-}$ However, false positive results should be avoided by not exceeding serum $\mathrm{CO}_{3} \mathrm{H}^{-}$concentration of $34 \mathrm{mEq} / \mathrm{L}$ or a urine $\mathrm{pH}$ of 7.8. On the other hand it should be noticed that patients unable to concentrate urine will show low urine $\mathrm{pCO}_{2}$ values in spite of normal acidification capacity.

PLASNA RENIN ACTIVITY IN THE URENIC-HEMOLITIC SYNDRONE. Grilnfeld Beatriz, Deymonaz Marisa, Liapchuck Sofía de, and Miendilaharzu J. Hospital de Niños.

Buenos Aires. Argentina.

The plasma renin activity (PRA) was studied in 19 children during the acute stage of the uremic-hemolitic symdrome (UHS). The PRA was increased in 17 of them on arrival, and continued to be abnormally high in 5 of 9 after the first diuresis, and in 4 of 8 after renal function returned to normal. The increase in PRA was of similar magnitude in pateints with predominant renal failure and in others with predominant hemolisis. There was no difference in PRA in 7 hypertensive children as compared to the others.

We conclude that the severity of the oliguric renal failure is not related necessarily to the PRA. Likewise systemic hyperiension is not related directly to PRA or the volume expansion that these children have. It remains to be shown what the role is of persistently high PRA in the behaviour of the blood pressure of patients that have had a UHS. 